\title{
Momentum flux and energy flux associated with internal gravity waves excited by the Assam-Burma hills in India
}

\author{
Prasanta Das $^{1} \cdot$ Somenath Dutta $^{2} \cdot$ Shyamal Kumar Mondal $^{3} \cdot$ Ansar Khan $^{4}$
}

Received: 17 January 2016/Accepted: 18 March 2016/Published online: 1 April 2016

(C) Springer International Publishing Switzerland 2016

\begin{abstract}
In this paper an attempt has been made to parameterize the momentum flux and energy flux associated with internal gravity waves excited by the AssamBurma hills in India in a baroclinic mean flow. For that a linear dynamical model for air flow across a three-dimensional meso-scale elliptical barrier has been used. In the present study $\mathrm{ABH}$ has been approximated by two 3-D elliptical barriers, separated by a valley of some finite distance and is broadly north-south (NS) oriented. For more simplicity, the basic flow has been assumed to have two components $\mathrm{U}$ and $\mathrm{V}$, normal to the major ridges of the elliptical barriers and parallel to the major ridges of the elliptic barriers respectively and a rectangular co-ordinate system in which, $x$-axis points towards east, $y$-axis points towards north and z-axis vertically upwards are considered. Realistic vertical variation of the buoyancy frequency (N) and both components of basic flow U and V have been considered in this study. Here two cases have been discussed. In every cases, the energy flux $\left(E_{z}\right)$ and the two horizontal components of the momentum flux $\tau_{\mathrm{zx}}$ (westerly) and $\tau_{z y}$ (easterly) are computed at different levels and have been compared with the results obtained by earlier investigators.
\end{abstract}

Ansar Khan

khanansargeo@gmail.com

1 Department of Mathematics, Ramananda College, Bishnupur, India

2 India Meteorological Department (IMD), Pune, India

3 Department of Applied Mathematics with Oceanology and Computer Programming, Vidyasagar University, Midnapore, India

4 Department of Geography and Environment Management, Vidyasagar University, Midnapore, India
Keywords Lee wave $\cdot$ Wave momentum flux $\cdot$ Wave energy flux

\section{Introduction}

It is a well established fact that, in every place weather and climate are substantially influenced by the presence of orographic barriers at that place. Influence of orographic barriers on airflow depends on the scale of the barrier as well as scale of flow. In a stably stratified atmosphere an air parcel, displaced vertically, undergoes buoyancy oscillation which gives rise to internal gravity waves (IGW). Now these IGW can propagate vertically to a great distance carrying energy from earth surface to the mean flow of wind and also carrying momentum from a stably stratified airstreams to higher levels in the atmosphere. Sometimes, they are associated with the formation of clear air turbulence (CAT). But this transport of energy or momentum by orographic gravity waves is a sub grid scale phenomena, yet its impact on large scale motion is substantial. So the parameterization of these sub grid scale fluxes is most important in the numerical weather prediction models.

Scorer $(1953,1954,1956)$ considered the flow over an isolated obstacle with both circular and oval cross-section parallel to the horizontal plane. He used a 2-D solution and succeeded in deriving approximate solutions for the isolated ridge by considering it to be composed of a set of ridges inclined at all angles to the flow and all intersecting at the peak. Sawyer (1959) first addressed the relative importance of the momentum loss, due to wave drag by meso-scale stationary lee waves in corporation with surface frictional drag over rough orographic terrain. He showed that a case of two dimensional flow over a bell-shaped obstacle and obtained the typical surface stress of the order 
1-10 dyne $/ \mathrm{cm}^{2}$. Eliassen and Palm (1961) obtained the vertical flux of horizontal momentum for 2-D gravity waves, which is independent of height, steady, laminar and non-dissipative. Blumen (1965) showed that the order of magnitude of the wave drag is sensible to the vertical wavelength and the maximum value of the drag is attained, when the vertical wavelength is twice the maximum height of the mountain. Smith (1978) obtained the pressure drag on the Blue-Ridge Mountain in the central Appalachians. He observed several periods with significant wave drag with pressure differences typically of the order of $50 \mathrm{~N} / \mathrm{m}^{2}$ across the ridge, during first two weeks of January 1974. Blumen and Dietze (1981) considered a 3-D linear hydrostatic model of stationary mountain wave in a stably stratified air stream. They took both the incoming basic flow and buoyancy frequency to be independent of height, but lateral variation of incoming flow was incorporated by assuming a hyperbolic secant profile $(U=\operatorname{sechy})$. They showed that the pressure pattern and velocity at the ground surface were similar in many respects to the field obtained by Smith (1978) for constant basic flow. Somieski (1981) studied the stratified hydrostatic flow over a 3-D circular mountain. He derived a 2 nd order wave equation from the primitive equation including constant rotation and vertical wind shear of the mean flow. He solved the equation numerically and showed that in case of no shear and constant static stability, the nodal lines are parabolic for circular mountain of diameter $50 \mathrm{~km}$. Blumen and Dietze (1982) extended their earlier model by including the vertical variation of the basic flow and static flow and static stability. They computed the energy flux and compared with the results of Eliassen and Palm (1961). Smith and Yuh-Lang (1982) had shown that in the presence of thermal forcing, the mountain drag is reversed and the momentum flux is strongly convergent at the heating level. They had confirmed the above theoretical findings of Eliassen and Palm (1961). Palmer et al. (1986) addressed the general westerly bias of the global general circulation models (GCM). Thy also pointed out that one way to reduce this general westerly bias is to incorporate the gravity wave drag parameterization scheme in the GCM.

In India the orographically excited internal gravity wave (IGW) problem have analyzed by Das (1964), Sarker(1965), De (1971, 1973), Sarker et al. (1978), Sinha Ray (1988), Tyagi and Madan (1989), Kumar et al. (1995) etc. Dutta (2001) considered 2-D half width of bell shaped part of the barrier across Mumbai-Pune section of the Western Ghats (WG) in an idealized air stream. He showed that both momentum flux and energy flux were independent of height and also shown that the plateau portion of the section dose not contribute to above fluxes. Dutta and Naresh
Kumar (2005) studied momentum and energy flux associated with 2-D mountain wave across Assam-Burma hills $(\mathrm{ABH})$. They showed that a long valley acts as a source in the atmospheric momentum budget and sink in the energy budget. Dutta (2007) considered 3-D realistic basic flow of both components (U, V) across Western Ghats (WG) and Khasi-Jayantia hills (KJ hills). He showed that for the WG, momentum flux is invariant in the vertical in absence of ' $\mathrm{V}$ ' components and also shown for KJ hills, momentum flux is invariant in vertical in absence of ' $\mathrm{V}$ ' component and divergent/convergent in presence of ' $\mathrm{V}$ ' component.

From the foregoing discussion it appears that, there are hardly any study made addressing the issue of parameterization of momentum flux and energy flux associated with internal gravity waves excited by Assam-Burma Hills, with realistic vertical profile of background wind and stability. In present study we have modified the Dutta (2007) model to make it suitable for parameterization of momentum flux and energy flux associated with IGW across ABH.

\section{Database}

Guwahati (26.190N Latitude and 91.730E Longitude) is the only Radio Sonde station to the upstream of both KJ hills and AB hills. Accordingly for the present study we have used the average of 0000UTC and 1200UTC RS/ RW data of Guahati for those dates, which corresponds to the observed lee waves across $\mathrm{ABH}$, as reported by De (1970, 1971) and Farooqui and De (1974) and has been obtained from Archive of India Meteorological Department, Pune.

\section{Methodology}

Let us consider a laminar, adiabatic, steady state, non rotational, non viscous, frictionless and Boussinesq 3-D baroclinic dry mean flow with realistic vertical variation of wind and temperature across the Assam-Burma hills $(\mathrm{ABH})$. It is assumed that basic flow consists of both zonal component (U), normal to the major ridges and meridional component (V), parallel to the major ridges. The BruntVaisala frequency $(\mathrm{N})$ and both components $(\mathrm{U}, \mathrm{V})$ are variant with height. Under the above assumptions the linearized governing equations may be written as:

$$
\begin{aligned}
& U \frac{\partial u^{\prime}}{\partial x}+V \frac{\partial u^{\prime}}{\partial x}+w^{\prime} \frac{d U}{d z}=-\frac{1}{\rho_{0}} \frac{\partial p^{\prime}}{\partial x} \\
& U \frac{\partial v^{\prime}}{\partial x}+V \frac{\partial v^{\prime}}{\partial x}+w^{\prime} \frac{d V}{d z}=-\frac{1}{\rho_{0}} \frac{\partial p^{\prime}}{\partial y}
\end{aligned}
$$


$U \frac{\partial w^{\prime}}{\partial x}+V \frac{\partial w^{\prime}}{\partial x}=-\frac{1}{\rho_{0}} \frac{\partial p^{\prime}}{\partial z}+g \frac{\theta^{\prime}}{\theta_{0}}$

$\frac{\partial u^{\prime}}{\partial x}+\frac{\partial v^{\prime}}{\partial y}+\frac{\partial w^{\prime}}{\partial z}=0$

$U \frac{\partial \theta^{\prime}}{\partial x}+V \frac{\partial \theta^{\prime}}{\partial y}+w^{\prime} \frac{d \theta_{0}}{d z}=0$

where, $U, V, \rho_{0}, \theta_{0}$ are respectively zonal state wind, meridional wind, density and potential temperature and $u^{\prime}, v^{\prime}, w^{\prime}, p^{\prime}, \theta^{\prime}$ are respectively the perturbation zonal wind, meridional wind, vertical wind, pressure and potential temperature. Since the perturbation quantities, $u^{\prime}, v^{\prime},-$ $w^{\prime}, p^{\prime}, \theta^{\prime}$ etc. are all continuous functions of $x, y, z$, hence their horizontal variation may be represented by a double Fourier integral, such as,

$u^{\prime}(x, y, z)=\frac{1}{4 \pi^{2}} \int_{-\infty}^{\infty} \int_{-\infty}^{\infty} \hat{u}(k, l, z) e^{i(k x+l y)} d k d l$

where $\hat{u}(k, l, z)=\int_{-\infty}^{\infty} \int_{-\infty}^{\infty} u^{\prime}(x, y, z) e^{-i(k x+l y)} d x d y$ is the double Fourier transform of $u^{\prime}(x, y, z)$. Performing double Fourier transform to (1) to (5), we get

$i(k U+l V) \hat{u}+\hat{w} \frac{d U}{d z}=-i k \frac{\hat{p}}{\rho_{0}}$

$i(k U+l V) \hat{v}+\hat{w} \frac{d V}{d z}=-i l \frac{\hat{p}}{\rho_{0}}$

$i(k U+l V) \hat{w}=-\frac{1}{\rho_{0}} \frac{\partial \hat{p}}{\partial z}+g \frac{\hat{\theta}}{\theta_{0}}$

$i k \hat{u}+i l \hat{v}+\frac{\partial \hat{w}}{\partial z}=0$

$i(k U+l V) \hat{\theta}+\hat{w} \frac{d \theta_{0}}{d z}=0$

Eliminating $\hat{u}, \hat{v}, \hat{p}, \hat{\theta}$ from the Eqs. (6)-(10) we get

$$
\begin{gathered}
\frac{\partial^{2} \hat{w}}{\partial z^{2}}+\frac{1}{\rho_{0}} \frac{d \rho_{0}}{\mathrm{dz}} \frac{\partial \hat{w}}{\partial z}+\left\{\frac{N^{2}\left(k^{2}+l^{2}\right)}{(k U+l V)^{2}}-\left(\frac{k \frac{d U}{d z}+l \frac{d V}{d z}}{k U+l V}\right) \frac{1}{\rho_{0}} \frac{d \rho_{0}}{\mathrm{dz}}\right. \\
\left.-\left(\frac{k \frac{d^{2} U}{d z^{2}}+l \frac{d^{2} V}{d z^{2}}}{k U+l V}\right)-\left(k^{2}+l^{2}\right)\right\} \hat{w}=0
\end{gathered}
$$

where $N=\sqrt{\frac{g}{\theta_{0}} \frac{d \theta_{0}}{d z}}$ is the Brunt-Vaisala frequency.

Now putting $\hat{w}(k, l, z)=\sqrt{\frac{\rho_{0}(0)}{\rho_{0}(z)}} \hat{w}_{1}(k, l, z)$ in Eq. (11), we get vertical structure equation

$\frac{\partial^{2} \hat{w}_{1}}{\partial z^{2}}+\left\{f(k, l, z)-\kappa^{2}\right\} \hat{w}_{1}=0$

where

$$
\begin{aligned}
f(k, l, z)= & \frac{N^{2}\left(k^{2}+l^{2}\right)}{(k U+l V)^{2}}-\left(\frac{k \frac{d U}{d z}+l \frac{d V}{d z}}{k U+l V}\right) \frac{1}{\rho_{0}} \frac{\mathrm{d} \rho_{0}}{\mathrm{dz}} \\
& -\left(\frac{k \frac{d^{2} U}{d z^{2}}+l \frac{d^{2} V}{d z^{2}}}{k U+l V}\right)+\frac{1}{4 \rho_{0}^{2}}\left(\frac{d \rho_{0}}{d z}\right)^{2}-\frac{1}{2 \rho_{0}} \frac{d^{2} \rho_{0}}{d z^{2}}
\end{aligned}
$$

and $\kappa^{2}=k^{2}+l^{2}$

It is very complicated to solve the Eq. (12) analytically. So, the Eq. (12) is solved quasi- numerically for the given wave number vectors $(k, l)$ of all vertical levels. The direction of the zonal wind changes from northerly to southerly during winter season at all levels (De 1973). The solution of (12) is strictly indeterminate unless the values of $f(k, l, z)$ specified at great height. Therefore it is assumed that above the upper boundary, $f(k, l, z)$ is constant. For simplicity, it is assumed that above the upper boundary, $f(k, l, z)=0$, which is similar to Sarker (1967), Dutta (2005, 2007), Sinha Ray (1988) etc.

Therefore the approximate solution of the Eq. (12) in the region $f(k, l, z)=0$ is of the form

$\hat{w}_{1}(k, l, z)=A e^{-\kappa z}$

where 'A' is an arbitrary constant. Since the pressure and vertical velocity are continuous function of $z$. So, $\hat{w}_{1}, \frac{\partial^{2} \hat{w}_{1}}{\partial z^{2}}$ are also continuous function of $\mathrm{z}$ in the region $f(k, l, z)=0$.

$\frac{\partial \hat{w}_{1}}{\partial z}=-\kappa \hat{w}_{1}$

Here the Eqs. (14) and (15) are the upper boundary conditions of the Eq. (12).

Now at the surface, the airflow follows the contour of the corner mountain, the profile is given by

$h(x, y)=\frac{h_{1}}{1+\frac{x^{2}}{a^{2}}+\frac{y^{2}}{b^{2}}}+\frac{h_{2}}{1+\frac{\left(x-d_{1}\right)^{2}}{a^{2}}+\frac{y^{2}}{b^{2}}}$

Here, $x$-axis parallel to the minor ridges of elliptical barriers and $y$-axis parallel to the major ridges of the elliptical barriers. For the Assam-Burma hills (ABH), major axis being NS oriented, $\mathrm{x}$-axis points towards east, $\mathrm{y}$-axis points towards north, $\mathrm{z}$-axis points vertically upwards and u-component of wind is towards east (westerly) and v-component is towards north (southerly). Profile of $\mathrm{ABH}$ barrier (16) is given by Fig. 1.

In the present study the values of $a, d_{1}, h_{1}$ and $h_{2}$ are same as those in De (1971) and $b=2.5 a$ as in Dutta (2005), as in Das et al. (2013). Therefore, we take $a=20 \mathrm{~km}, b=2.5 a, d_{1}=45 \mathrm{~km}, h_{1}=0.9 \mathrm{~km} \quad$ and $h_{2}=0.7 \mathrm{~km}$. If $\hat{h}(k, l)$ be the double Fourier transformation of $h(x, y)$, then expression of $\hat{h}(k, l)$ given as 
Fig. 1 Profile of Assam Burma hills

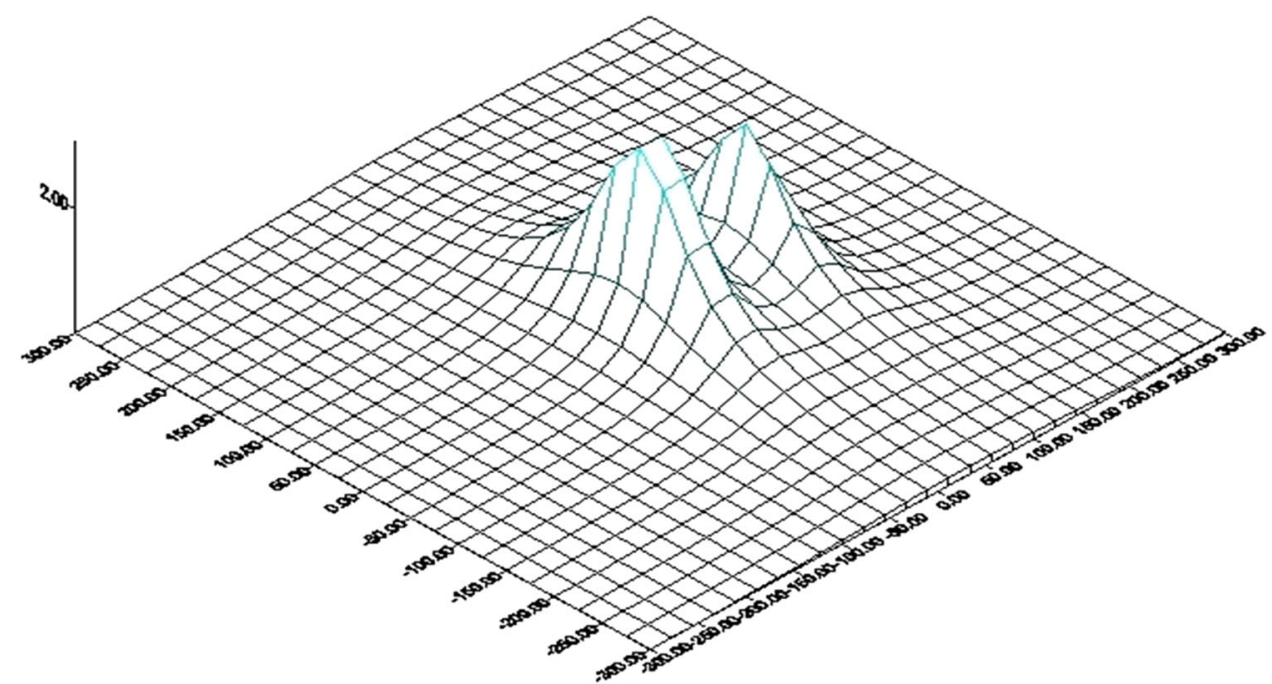

$\hat{h}(k, l)=2 \pi a b\left(h_{1}+h_{2} e^{-i k d_{1}}\right) K_{0}\left(\sqrt{a^{2} k^{2}+b^{2} l^{2}}\right)$

Details of the above derivation is given in Appendix. Now to solve Eq. (12), an arbitrary function $\psi(k, l, z)$ have been considered, which satisfies the Eq. (12) as well as boundary conditions (14) and (15) at $z=z_{1}=n d$.

Therefore, $\frac{\partial^{2} \psi}{\partial z^{2}}+\left\{f(k, l, z)-\kappa^{2}\right\} \psi=0$

And $\frac{\partial \psi}{\partial z}=-\kappa \psi$

For convenience we assumed that $\psi(k, l, n d)=1$. Hence both $\psi(k, l, z)$ and $\hat{w}_{1}(k, l, z)$ are solutions of the second order linear homogeneous equation

$\frac{\partial^{2} \varphi}{\partial z^{2}}+\left\{f(k, l, z)-\kappa^{2}\right\} \varphi=0$

Now the Wronskian $W\left(\hat{w}_{1}, \psi, z\right)$ of $\hat{w}_{1}$ an $\psi$ at $z=z_{1}=n d$ is

$$
\begin{aligned}
\left|\begin{array}{cc}
\hat{w}_{1} & \psi \\
\frac{\partial \hat{w}_{1}}{\partial z} & \frac{\partial \psi}{\partial z}
\end{array}\right|_{z=z_{1}}= & \hat{w}_{1}\left(k, l, z_{1}\right) \frac{\partial \psi\left(k, l, z_{1}\right)}{\partial z} \\
& -\psi\left(k, l, z_{1}\right) \frac{\partial \hat{w}_{1}\left(k, l, z_{1}\right)}{\partial z} \\
= & -\hat{w}_{1}\left(k, l, z_{1}\right) \kappa \psi\left(k, l, z_{1}\right)+\hat{w}_{1}\left(k, l, z_{1}\right) \\
& \kappa \psi\left(k, l, z_{1}\right) \\
= & 0
\end{aligned}
$$

From the Wronskian result we can say that both $\psi(k, l, z)$ and $\hat{w}_{1}(k, l, z)$ are not linearly independent solutions of Eq. (20) at $z=z_{1}=n d$.

Hence they are not linearly independent at every point of the model vertical domain. So $\hat{w}_{1}(k, l, z)$ can expressed as following $\hat{w}_{1}(k, l, z)=A \psi(k, l, z)$ at $0 \leq z \leq z_{1}$

where ' $A$ ' is an arbitrary constant. Now the linearized lower boundary condition (at $z=0$ ) for $w^{\prime}{ }_{1}$ is given by

$$
\begin{aligned}
w_{1}^{\prime}(x, y, 0) & =w^{\prime}(x, y, 0) \\
& =U(0) \frac{\partial h(x, y, 0)}{\partial x}+V(0) \frac{\partial h(x, y, 0)}{\partial y}
\end{aligned}
$$

Therefore

$\hat{w}_{1}(k, l, 0)=i\{k U(0)+l V(0)\} \hat{h}(k, l)$

Using the above boundary conditions and following Dutta $(2005,2007)$ we have evaluated the value of arbitrary constant 'A' and then the Eq. (12) have been solved quasi-numerically. Therefore the solution for $\hat{w}_{1}(k, l, z)$ is

$\hat{w}_{1}(k, l, z)=i\{k U(0)+l V(0)\} \hat{h}(k, l) \frac{\psi(k, l, z)}{\psi(k, l, 0)}$

Therefore

$\hat{w}(k, l, z)=\sqrt{\frac{\rho_{0}(0)}{\rho_{0}(z)}} i\{k U(0)+l V(0)\} \hat{h}(k, l) \frac{\psi(k, l, z)}{\psi(k, l, 0)}$

Following Dutta $(2005) \psi(k, l, z)$ has been computed numerically at different vertical levels and different vertical grid points, at intervals of $d=0.25 \mathrm{~km}$, for a given wave number vector $(k, l)$.Using the values of $\psi$ and using (24), $\hat{w}(k, l, z)$ can be found at discrete levels for given wave number vectors $(k, l)$.

Now we obtain $\hat{p}, \hat{u}$ and $\hat{v}$ from Eqs. (6), (7), (8) and (10) by following Dutta $(2005,2007)$.

$\hat{p}(k, l, z)=\frac{i\left\{\left(k \frac{d U}{d z}+l \frac{d V}{d z}\right) \hat{w}(k, l, z)-(k U+l V) \frac{\partial \hat{w}}{\partial z}\right\} \rho_{0}(z)}{\kappa^{2}}$ 


$$
\begin{aligned}
& \hat{u}(k, l, z) \\
& =\frac{i\left[\hat{w}(k, l, z) \frac{d U}{d z}+\frac{k}{\kappa^{2}}\left\{\left(k \frac{d U}{d z}+l \frac{d V}{d z}\right) \hat{w}(k, l, z)-(k U+l V) \frac{\partial \hat{w}}{\partial z}\right\}\right]}{(k U+l V)}
\end{aligned}
$$

$$
\begin{aligned}
& \hat{v}(k, l, z) \\
& =\frac{i\left[\hat{w}(k, l, z) \frac{d V}{d z}+\frac{k}{\kappa^{2}}\left\{\left(k \frac{d U}{d z}+l \frac{d V}{d z}\right) \hat{w}(k, l, z)-(k U+l V) \frac{\partial \hat{w}}{\partial z}\right\}\right]}{(k U+l V)}
\end{aligned}
$$

By performing inverse double Fourier transformation on Eqs. (24)-(27) numerically, we obtain $w^{\prime}, p^{\prime}, u^{\prime}, v^{\prime}$ at each horizontal grid point $(5 \mathrm{~km}$ apart) at each vertical level. Following Dutta (2007), then the two horizontal components of the momentum flux vector, viz., $\tau_{z x}=\overline{\bar{u} \dot{u}}$, $\tau_{z y}=\overline{\overline{\hat{v} \dot{w}}}$ and energy flux $E_{z}=\overline{\bar{p} \dot{w}}$ at any vertical level and any horizontal grid point have been computed, where $\overline{\overline{()}}$ indicates the average surface area ' $S$ ' of the given mountain barrier (16). Here the average surface area is $S=\frac{1}{2}\left(h_{1}+h_{2}\right)\left\{\pi^{2}(a+b)+d_{1}\right\}$ (following Dutta 2007).

\section{Results and discussion}

De (1973) observed that the airstream characteristic across the Assam-Burma hills (ABH) during winter season is favourable for the occurrence of the lee waves. Also Dutta and Naresh Kumar (2005) and Das et al. (2013) have shown that the air stream during winter season is favourable for the occurrence of the lee waves across the ABH. In this section following two selected cases for the $\mathrm{ABH}$ have been studied.

\section{Case-1: 23rd November 1966 (winter season)}

The vertical profiles of two components of basic flow $\mathrm{U}(\mathrm{z})$, $\mathrm{V}(\mathrm{z})$ and temperature $\mathrm{T}(\mathrm{z})$ in the undisturbed flow shown in Fig. 2a, which are based on the average of 0000UTC and 1200UTC RS/RW data of Guahati for that date during winter season. This figure shows that the profile of temperature $T(z)$ is constant lapse rate with vertical, hence following Sarker (1967) and Dutta $(2005,2007) \mathrm{T}(\mathrm{z})$ has been approximated the pseudo-adiabatic line through the surface dry bulb temperature. Using this profile the vertical energy flux $\left(E_{z}\right)$ and two horizontal components of momentum flux $\tau_{\mathrm{zx}}$ and $\tau_{\mathrm{zy}}$ are computed at different levels.

The energy flux $\left(E_{z}\right)$ is invariant in the vertical above $z=2.3 \mathrm{~km}$ in the presence of ' $\mathrm{V}$ ' component and $E_{z}$ is also invariant in the vertical above $z=1.8 \mathrm{~km}$ in the absence of ' $\mathrm{V}$ ' component, shown in Fig. 2b. It is seen that at the lower levels up to $z=0.5 \mathrm{~km}$ and in the layer from $z=1.5 \mathrm{~km}$ to $z=2.3 \mathrm{~km}, E_{z}$ is vertically upward and in the layer from $z=0.5 \mathrm{~km}$ to $z=1.5 \mathrm{~km}, E_{z}$ is vertically downward in the presence of ' $\mathrm{V}$ ' component and at the lower levels up to $z=1.8 \mathrm{~km}, E_{z}$ is vertically downward in absence of ' $\mathrm{V}$ ' component. Figure $2 \mathrm{~b}$ also shows that the divergence/convergence of $E_{z}$ in the layer up to $z=2.3 \mathrm{~km}$, when ' $\mathrm{V}$ ' is present or not.

The vertical profile of westerly-momentum flux $\left(\tau_{\mathrm{zx}}\right)$ shown in Fig. 2c. It shows that the momentum flux $\tau_{\mathrm{zx}}$ is non divergent and it is almost nil throughout vertical in the absence of ' $V$ ' component. It is seen (Fig. 2c) that in presence of ' $\mathrm{V}$ ' component, the momentum flux $\tau_{\mathrm{zx}}$ is convergent/divergent and vertically upward in the layer from surface to $z=2.8 \mathrm{~km}$ and above which it is invariant in the vertical.

The vertical profile of southerly-momentum flux $\left(\tau_{z y}\right)$ is shown in Fig. 2d. From this figure, it is seen that, the momentum flux $\left(\tau_{\mathrm{zy}}\right)$ is invariant in the vertical above $z=2.2 \mathrm{~km}$, whether ' $\mathrm{V}$ ' component is present or not. It is also shown that the momentum flux $\left(\tau_{\mathrm{zy}}\right)$ is divergent/convergent and vertically upward in the presence of ' $\mathrm{V}$ ' component.

Dutta and Naresh Kumar (2005) have shown the vertical flux energy/momentum across $\mathrm{ABH}$ as the contribution of those two ridges with a slight lick of them across the valley. In the present study, all the vertical fluxes energy/momentum across $\mathrm{ABH}$ are in conformity with Dutta and Naresh kumar (2005).

\section{Case-2: 9th January 1967 (winter season)}

The vertical profiles of $\mathrm{U}(\mathrm{z}), \mathrm{V}(\mathrm{z})$ and $\mathrm{T}(\mathrm{z})$ in the undisturbed flow are shown in Fig. 3a, which are based on the average of 0000UTC and 1200UTC RS/RW data of Guahati of 9th January 1967 during winter season. The figure shows that the profile of temperature $\mathrm{T}(\mathrm{z})$ is constant moist adiabatic lapse rate with vertical, and hence following Sarker (1967) and De (1971), T(z) is approximated by the pseudo-adiabatic line through the surface dry bulb temperature. Using this profile, the vertical energy flux $\left(E_{z}\right)$ and the two horizontal components of the momentum flux $\tau_{\mathrm{zx}}$ and $\tau_{\mathrm{zy}}$ at different levels have been computed.

The vertical profile of the energy flux $\left(E_{z}\right)$ has been shown in Fig. 3b. It is seen that the energy flux $\left(E_{z}\right)$ is invariant in vertical above $z=2.6 \mathrm{~km}$, whether ' $\mathrm{V}$ ' is present or not. It is also shown (Fig. 3b) that from the surface to $z=2 \mathrm{~km}$ and from $z=2 \mathrm{~km}$ to $z=2.6 \mathrm{~km}$ the energy flux $\left(E_{z}\right)$ is upward and downward respectively in presence of ' $\mathrm{V}$ ' component and also in the absence of ' $\mathrm{V}$ ' component the energy flux $\left(E_{z}\right)$ is vertically upward. Figure $3 \mathrm{~b}$ also shows that divergence/convergence of $E_{z}$ in the layer up to $2.6 \mathrm{~km}$, when ' $\mathrm{V}$ ' component is present or not. 
a

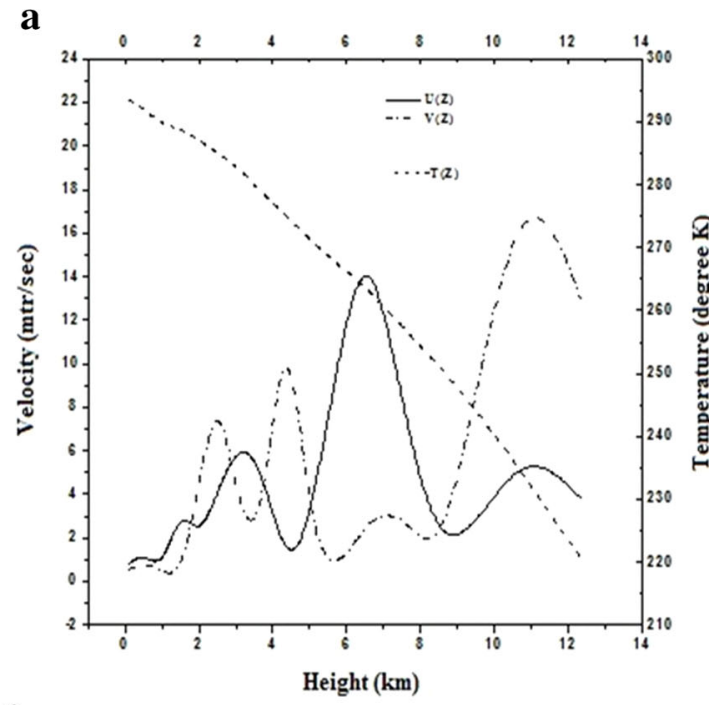

c

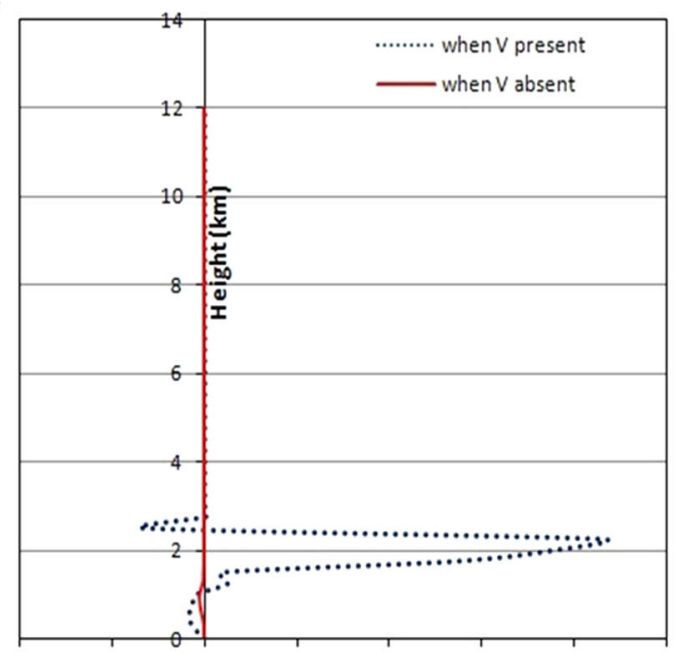

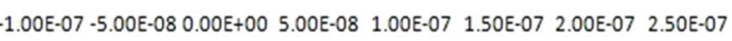
$\mathrm{N} / \mathrm{msq}$

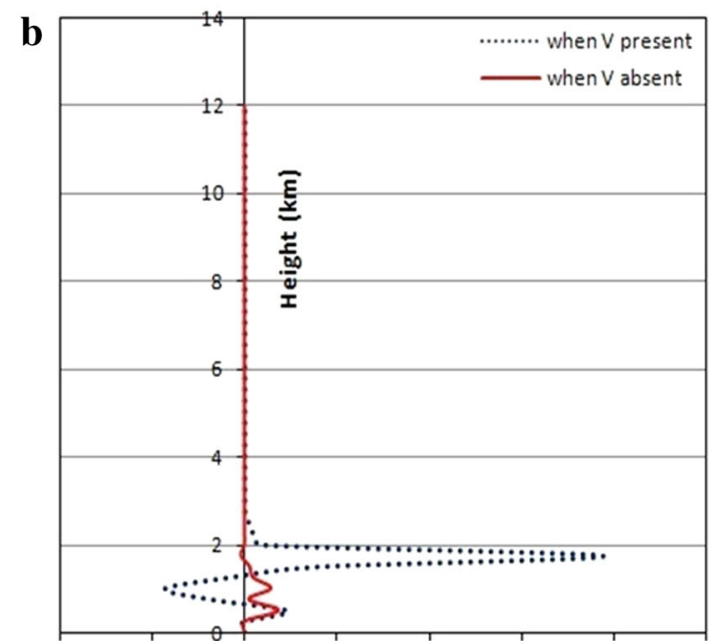

$-4.00 E-02-2.00 E-02 \quad 0.00 E+00 \quad 2.00 E-02 \quad 4.00 E-02 \quad 6.00 E-02 \quad 8.00 E-02 \quad 1.00 E-01$

d

Watt/msq)

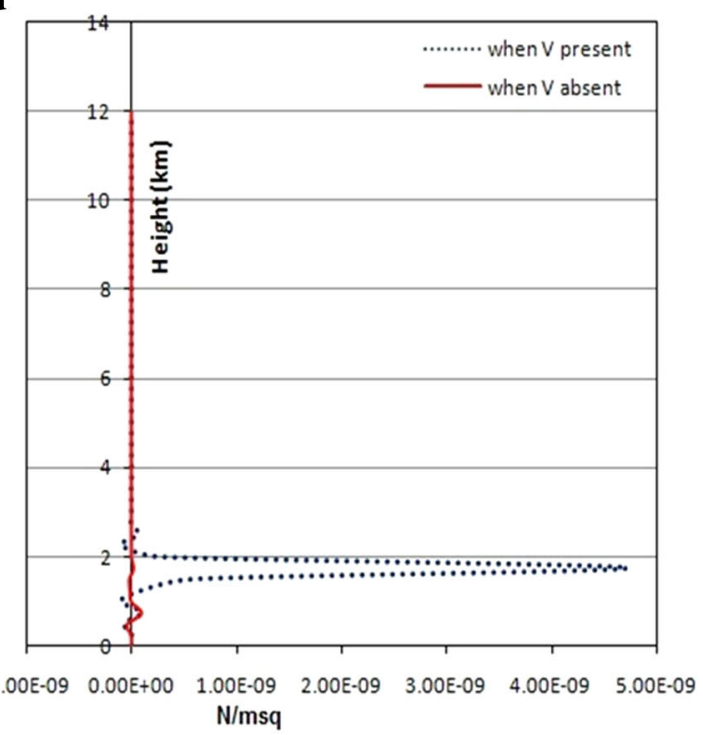

Fig. 2 a Vertical profile of U,V, T on 23.11.66, b vertical profile of energy flux $\left(E_{z}\right)$ on 23.11.66, $\mathbf{c}$ vertical profile of westerly- momentum flux $\left(\tau_{\mathrm{zx}}\right)$ on 23.11.66, $\mathbf{d}$ vertical profile of southerly-momentum flux $\left(\tau_{\mathrm{zy}}\right)$ on 23.11.66

Figure $3 \mathrm{c}$ shows that the vertical profile of westerlymomentum flux $\left(\tau_{\mathrm{zx}}\right)$ is convergent/divergent in the layer up to $z=2.7 \mathrm{~km}$ and is invariant in the vertical above $z=2.7 \mathrm{~km}$ in the presence of ' $\mathrm{V}$ ' component or not. It is seen (Fig. 3c) that $\tau_{\mathrm{zx}}$ is vertically downward in the layer from $z=1.8 \mathrm{~km}$ to $z=2.7 \mathrm{~km}$ and upward in the layer from surface to $z=1.8 \mathrm{~km}$ in the presence of ' $\mathrm{V}$ ' component and also vertically downward in the layer from surface to $z=2.7 \mathrm{~km}$ in absence of ' $\mathrm{V}$ ' component.

Whether ' $\mathrm{V}$ ' component is present or not, the southerlymomentum flux $\left(\tau_{\mathrm{zy}}\right)$ is invariant with vertical above $z=2.8 \mathrm{~km}$, shown in Fig. 3d. In the presence of ' $\mathrm{V}$ ' component the momentum flux $\left(\tau_{\mathrm{zy}}\right)$ is convergent/divergent and is enhanced. The Fig. $3 \mathrm{~d}$ also shows that $\tau_{\mathrm{zy}}$ is vertically downward in the layer from surface to $z=2 \mathrm{~km}$ and vertically upward in the layer from $z=2 \mathrm{~km}$ to $z=2.8 \mathrm{~km}$ when ' $\mathrm{V}$ ' component is present.

Dutta (2001) considered the profile of Mumbai-Pune section of Western-Ghats (WG) and there was only one ridge and a plateau. He showed that the plateau portion does not contribute to the fluxes of energy or momentum. In the present study, two ridges and a valley of the profile of $\mathrm{ABH}$ have contributed to the fluxes of energy or momentum.

\section{Conclusions}

In this investigation, we have presented the wave momentum flux and energy flux for 3-D meso-scale lee wave across the Assam-Burma hills following a quasi- 
a

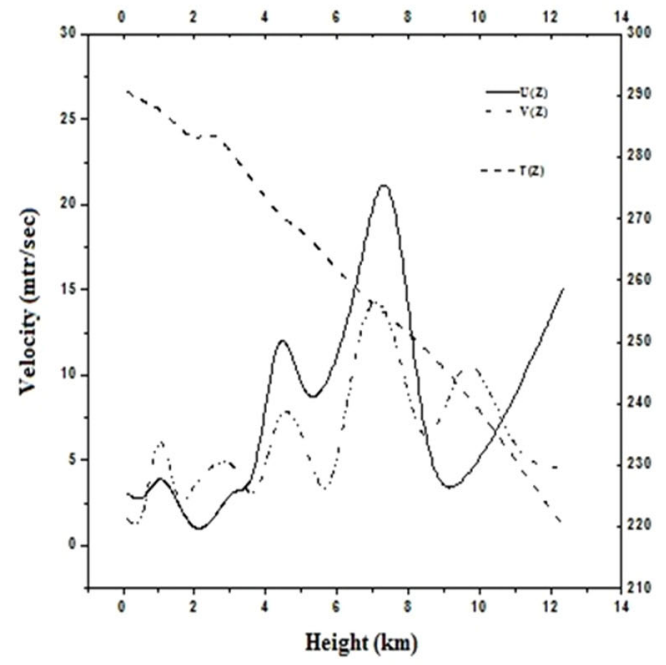

c

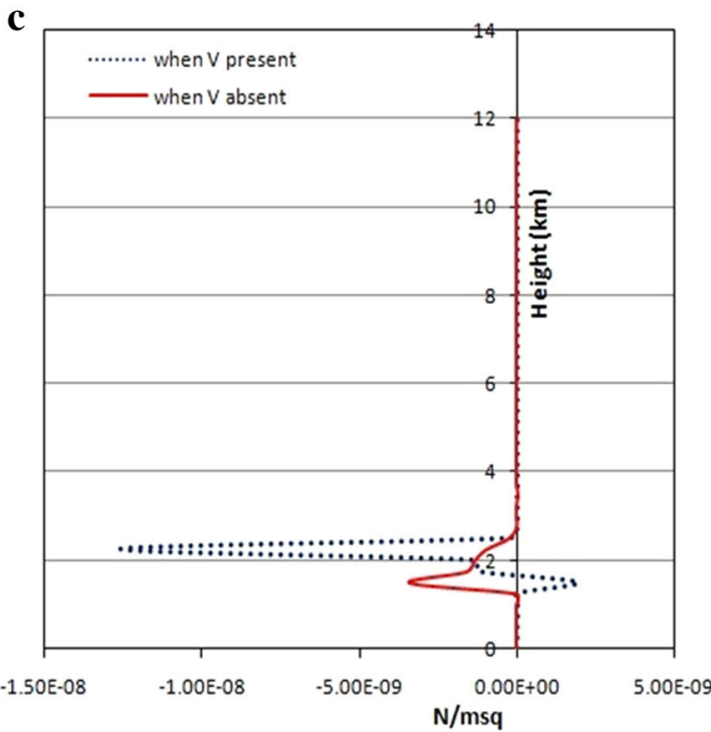

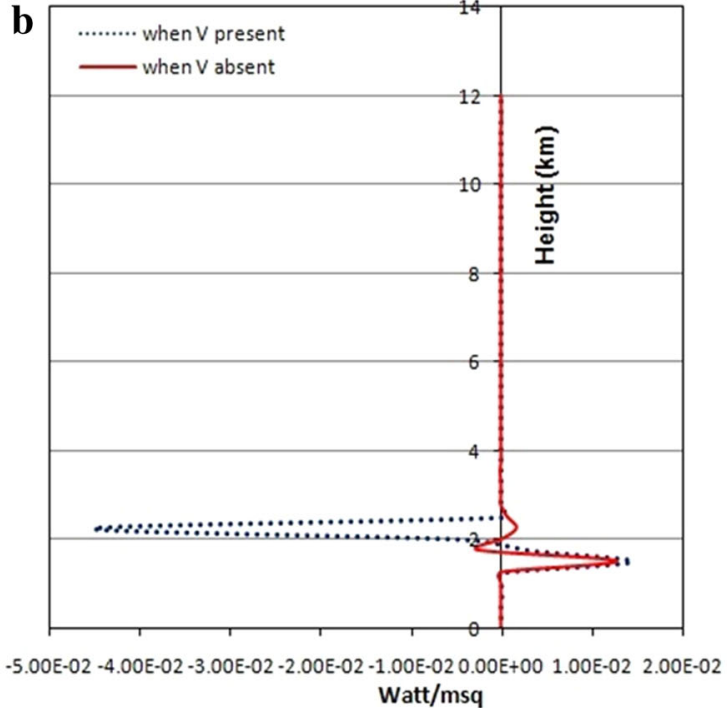

d

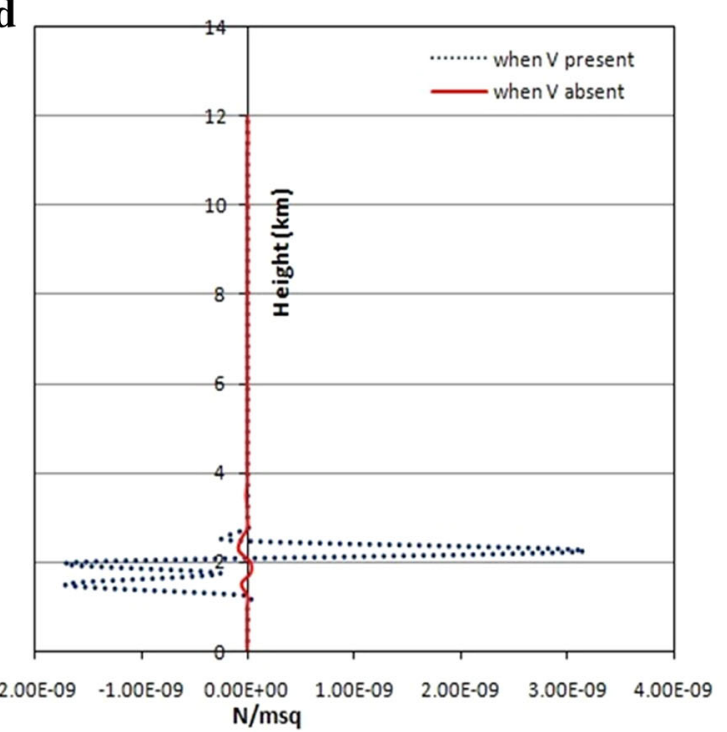

Fig. 3 a Vertical profile of U,V, T on 09.01.67, b vertical profile of energy flux $\left(E_{z}\right)$ on 09.01.67, $\mathbf{c}$ vertical profile of westerly-momentum flux $\left(\tau_{\mathrm{zx}}\right)$ on 09.01 .67 , $\mathbf{d}$ vertical profile of southerly-momentum flux $\left(\tau_{\mathrm{zy}}\right)$ on 09.01 .67

numerical approach. In the sequel, we have made some interesting observation. Moreover,

From the study of two cases presented in this paper, it is found that the fluxes vary in the vertical but the vertical variation is not uniform with height. In the some layers, fluxes are upward and somewhere fluxes are downward. But in one case energy flux $\left(E_{z}\right)$ is upward and in another case it is downward, but in the most of cases the momentum fluxes are upward.

In the both cases, the effects of ' $\mathrm{V}$ ' component of the basic flow have been observed. This component makes the energy flux $\left(E_{z}\right)$ or momentum fluxes $\left(\tau_{\mathrm{zx}}, \tau_{\mathrm{zy}}\right)$ divergent/convergent in the vertical.

In absence of ' $\mathrm{V}$ ' component the, southerly-momentum flux $\left(\tau_{\mathrm{zy}}\right)$ is non-divergent and the presence of ' $\mathrm{V}$ ' makes $\tau_{\mathrm{zy}}$ divergent/convergent. Also the westerly-momentum flux $\left(\tau_{\mathrm{zx}}\right)$ is convergent/divergent, whether ' $\mathrm{V}$ ' component is present or not.

The above model may be used for any 3-D mountain profile to compute the energy flux $\left(E_{z}\right)$ and two horizontal components of the momentum fluxes $\left(\tau_{\mathrm{zx}}\right.$ and $\left.\tau_{\mathrm{zy}}\right)$ at different levels.

Acknowledgments Authors are grateful to Dr. U.S. De, Former Addl. Director General of Meteorology of India Meteorological Department and Prof. Manoranjan Maiti, Department of Applied Mathematics with Oceanology and Computer Programming, Vidyasagar University, Midnapore, India for their kind valuable suggestions and guidance. Second author is thankful to all personnel at Meteorological Training Institute, IMD, Pune for their valuable supports. 


\section{Appendix}

The Fourier Transform of the function $h(x, y)=\frac{h_{1}}{1+\frac{x^{2}}{a^{2}}+\frac{y^{2}}{b^{2}}}+$ $\frac{h_{2}}{1+\frac{\left(x-d_{1}\right)^{2}}{a^{2}}+\frac{y^{2}}{b^{2}}}$ is given by

$$
\begin{aligned}
F\{h(x, y)\}= & \int_{-\infty}^{\infty} \int_{-\infty}^{\infty} h(x, y) e^{-i(k x+l y)} d x d y \\
\hat{h}(k, l)= & \int_{-\infty}^{\infty} \int_{-\infty}^{\infty}\left\{\frac{h_{1}}{1+\frac{x^{2}}{a^{2}}+\frac{y^{2}}{b^{2}}}+\frac{h_{2}}{1+\frac{\left(x-d_{1}\right)^{2}}{a^{2}}+\frac{y^{2}}{b^{2}}}\right\} e^{-i(k x+l y)} d x d y \\
\hat{h}(k, l)= & a b \int_{-\infty}^{\infty} \int_{-\infty}^{\infty} \frac{h_{1} e^{-i(k x+l y)}}{1+\frac{x^{2}}{a^{2}}+\frac{y^{2}}{b^{2}}} d x d y \\
& +\int_{-\infty}^{\infty} \int_{-\infty}^{\infty} \frac{h_{2} e^{-i(k x+l y)}}{1+\frac{\left(x-d_{1}\right)^{2}}{a^{2}}+\frac{y^{2}}{b^{2}}} d x d y
\end{aligned}
$$

Putting $x=a X, y=b Y$ for the first term and $x-d_{1}=a X, y=b Y$ for the 2nd term.

And $k=\frac{k^{\prime}}{a}, l=\frac{l^{\prime}}{b}$ for the both terms and we get the following

$$
\begin{aligned}
\hat{h}(k, l)= & a b \int_{-\infty}^{\infty} \int_{-\infty}^{\infty} \frac{h_{1} e^{-i\left(k^{\prime} X+l^{\prime} Y\right)}}{1+X^{2}+Y^{2}} d X d Y+a b e^{-i^{l^{\prime} d_{1}} a} \\
& \times \int_{-\infty}^{\infty} \int_{-\infty}^{\infty} \frac{h_{2} e^{-i\left(k^{\prime} X+l^{\prime} Y\right)}}{1+X^{2}+Y^{2}} d X d Y \\
\hat{h}(k, l)= & a b\left(h_{1}+h_{2} e^{-i k d_{1}}\right) \int_{-\infty}^{\infty} \int_{-\infty}^{\infty} \frac{e^{-i\left(k^{\prime} X+l^{\prime} Y\right)}}{1+X^{2}+Y^{2}} d X d Y
\end{aligned}
$$

Putting $X=r \cos \theta, Y=r \sin \theta$ and $k^{\prime}=\kappa \cos \alpha, l^{\prime}=$ $\kappa \sin \alpha$ we get

$\hat{h}(k, l)=a b\left(h_{1}+h_{2} e^{-i k d_{1}}\right) \int_{0}^{\infty} \int_{0}^{2 \Pi} \frac{e^{-i r \kappa \cos (\theta-\alpha)}}{1+r^{2}} r d r d \theta$

Now $\int_{0}^{2 \Pi} e^{-i r \kappa \cos (\theta-\alpha)} d \theta=2 \Pi J_{0}(r \kappa)$ [taken from Dutta et al. (2002)]

And $\int_{0}^{\infty} \frac{\mathrm{J}_{0}(\mathrm{r \kappa})}{1+r^{2}} r d r=K_{0}(\kappa)$ [taken from Dutta et al. (2002)]

Where $\mathrm{J}_{0}(r \kappa)$ and $K_{0}(\kappa)$ are Bessel function of 1 st and 2nd kind of order zero respectively.

Hence $\quad \hat{h}(k, l)=2 \pi a b\left(h_{1}+h_{2} e^{-i k d_{1}}\right) K_{0}(\kappa), \quad$ where $\kappa=\sqrt{a^{2} k^{2}+b^{2} l^{2}}$

Therefore $\hat{h}(k, l)=2 \pi a b\left(h_{1}+h_{2} e^{-i k d_{1}}\right) K_{0}\left(\sqrt{a^{2} k^{2}+b^{2} l^{2}}\right)$.

\section{References}

Blumen W (1965) A random model of momentum flux by mountain waves. Geofys Publ 26:1-33

Blumen W, Dietze SC (1981) An analysis of three- dimensional mountain lee waves in a stratified shear flow. J Atmos Sci 38:1949-1963

Blumen W, Dietze SC (1982) An analysis of three- dimensional mountain lee waves in a stratified shear flow, Part-II. J Atmos Sci 39:2712-2720

Das PK (1964) Lee waves associated with a large circular mountain. Indian J Meteorol Geophys 15:547-554

Das Prasanta, Mondal Shyamal Kumar, Dutta Somenath (2013) Asymptotic solution for 3-D Lee waves across Assam-Burma hills. Mausam 64(3):501-516

De US (1970) Lee waves as evidenced by satellite cloud pictures. IJMG 21(4):637-642

De US (1971) Mountain waves over northeast India and neighbouring regions. Indian J Meteorol Geophys 22:361-364

De US (1973) Some studies on mountain waves, Ph.D. thesis, Banaras Hindu University, India

Dutta S (2001) Momentum flux, energy flux and pressure drag associated with mountain wave across western ghats. Mausam 52(2):325-332

Dutta S (2005) Effect of static stability on the pattern of 3-D baroclinic lee wave across a meso-scale elliptical barrier. Meteorol Atmos Phys 90:139-152

Dutta S (2007) Parameterization of momentum flux and energy flux associated with orographically excited internal gravity waves in a baroclinic background flow. Mausam 58(4):459-470

Dutta S, Kumar Naresh (2005) Theoretical studies of momentum flux and energy flux associated with mountain wave across the Assam-Burma hills in an idealized atmosphere. Mausam 56(3):527-534

Dutta S, Maiti M, De US (2002) Waves to the lee of a meso-scale elliptic orographic barrier. Meteorol Atmos Phys 81(3-4): 219-235

Eliassen A, Palm E (1961) On the transfer of energy in stationary mountain waves. Geophys. publ. 22(3):1-23

Farooqui SMT, De US (1974) A numerical study of the mountain wave problem. Pure Appl Geophys 112:289-300

Kumar P, Singh MP, Padmanabhan N, Natarajan N (1995) Effect of latent heat release on mountain waves in a sheared flow. Mausam 46:111-126

Palmer TN, Shutts GJ, Swinbank R (1986) Alleviation of a systematic westerly bias in general circulation and numerical weather prediction models through an orographic gravity wave drag parameterization. Quart J R Met Soc 112:1001-1039

Sarker RP (1965) A theoretical study of mountain waves on western Ghats. I J Met Geophys 16(4):565-584

Sarker RP (1967) Some modifications in a dynamical model of orographic rainfall. Mon Wea Rev. 95:673-684

Sarker RP, Sinha Ray KC, De US (1978) Dynamics of orographic rainfall. Indian J Meteorol Geophys 29:335-348

Sawyer JS (1959) The introduction of the effects of topography into methods of numerical forecasting. Quart J R Met Soc 85:31-43

Scorer RS (1953) Theory of airflow over mountain, II: The flow over a ridge. Quart J R Met Soc 79:70-83

Scorer RS (1954) Theory of airflow over mountain, III: Airflow characteristics. Quart J R Met Soc 80:417-428

Scorer RS (1956) Airflow over an isolated hill. Quart J R Met Soc 82:75-81

Sinha Ray KC (1988) Some studies on effects of Orography on airflow and rainfall, Ph.D. thesis, University of Pune, India 
Smith RB (1978) A measurement of mountain drag. J Atmos Sci 35(9):1644-1654

Smith RB, Lin Yuh-Lang (1982) The addition of latent heat to stratified air stream with application to the dynamics of orographic rain. Quart J R Meteor Soc 61:1040-1054
Somieski F (1981) Linear theory of three-dimensional flow over mesoscale mountains. Beitr Phys Atmos 54(3):315-334

Tyagi A, Madan OP (1989) Mountain waves over Himalayas. Mausam 40:181-184 